INTERNATIONAL DESIGN CONFERENCE - DESIGN 2018

https://doi.org/10.21278/idc.2018.0224

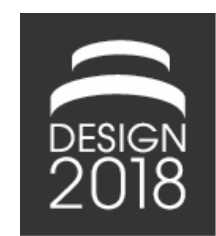

\title{
RECONCEPTUALIZING DESIGN RISK MANAGEMENT AS A LEARNING STRATEGY
}

\author{
P. L. Willumsen, J. Oehmen and S. K. Ernstsen
}

\begin{abstract}
We observed how risk management (RM) is perceived to hinder radical innovation in companies. RM is perceived to kill good ideas too early before they were explored thoroughly or leads to cancellation of projects after several years of development time due to critical risks. This paper contributes an empirical investigation and show that a multitude of value propositions for RM exist, among them innovation. The paper proposes 5 practices to reconcile risk management and innovation, and reconceptualise risk management as a learning strategy that supports innovation.
\end{abstract}

Keywords: risk management, innovation management, systems engineering (SE), product development

\section{Introduction: The relationship of innovation and risk management}

There is an inherent link between risk management and innovation management, and arguably the word 'risk', derived from the early Italian 'risicare' which means 'to dare', describes both. Both in literature and in our empirical studies (Section 3), we observed how design project risk management is perceived to hinder radical innovation in companies. We argue in this paper that risk management is not necessarily conducive to innovation management and that they have not been able to integrate and benefit fully from each other yet. However, our research uncovered instances where this integration was achieved and design risk management became an integral part of innovation management. We argue in this paper that the key step to achieving this integration is to re-conceptualize risk management as an activity that dramatically reduces the cost of learning in innovation management. Semantically, innovation and risk management are often discussed together, for example: "One aspect of this [radical innovation] dimension appears to be whether or not the innovation incorporates technology that is a risky departure from existing practice" (Ettlie et al., 1984). The management of radical innovation deals with high degrees of uncertainty, future options, potential disruptions and paradigm shifts (Dodgson, 2013) and managing risk is essential for technological innovation (Dodgson et al., 2008). A key aspect of Innovation management is addressing uncertainty and the willingness or appetite to engage with uncertain technologies and markets (Sharma, 1999; Dodgson et al., 2008; Dodgson, 2013). Central characteristics of innovation management include: 1. Creating options through searching an opportunity space, internally and externally. 2. Selecting innovations to pursue through risk assessment. 3. Configure and deploy resources defined by the company's absorptive capacity, and 4. Capture value, build capabilities and learn through evaluating performance and returns (Sharma, 1999; Dodgson et al., 2008; Dodgson, 2013). As they argue, when the degree of innovation is high, it is especially hard but important for the idea developers to identify and learn about technological and market potential by assessing risk and uncertainty. We argue that both innovation management of radical innovation ideas and risk 
management are processes that deal with managing and understanding uncertainty. While semantically often linked, we argue in the following that this integration is often lacking on a process level:

A literature review showed that the study of innovation risk management is underdeveloped, both academically and in terms of case studies. While risk management is frequently acknowledged in innovation management, there is little discussion on how it should actually be executed, or integrated into innovation management. (Boothe, 2014; Bowers and Khorakian, 2014; Neumann, 2016) However, both innovation management of radical innovation ideas and risk management are processes that deal with managing uncertainty: It can be easily imagined that they clash (Sharma, 1999), if risk management is seen as a process that excludes high-risk options. In our understanding, there is no fundamental reason why risk management cannot support managing high-risk undertakings. Literature discusses how design project risk management is perceived to hinder radical innovation in companies (see Section 4 for a detailed review of the literature) and risk management is often perceived as "risk-adverse" in innovation (Sharma, 1999; Loch et al., 2006). We observed two failure modes discussed in the literature: Either risk management is perceived to kill good concepts too early before they were explored thoroughly (Sharma, 1999; Dodgson, 2013). Alternatively, a lack of risk management in the early phases leads to cancellation of projects after several years of development time due to unresolved and often undiscovered critical risks, with a general sentiment that an earlier involvement of risk management(RM) could have identified and resolved the risk (Boothe, 2014; Bowers and Khorakian, 2014; Neumann, 2016; Haughey, 2017).

Risk management is an important aspect of design and design-related processes and project management (Olechowski et al., 2012; PMI, 2013). Risk management is about understanding and managing the effect of uncertainty on objectives (ISO, 2009) and addressing them appropriately (Paté-Cornell, 1996), for instance through acquiring knowledge (Oehmen and Seering, 2011). The ISO 31000 risk management standard argues that a key principle of risk management is to "create and protect value".

In order to conceptualize the relationship of risk management and innovation management, we review the value propositions of risk management in Section 3. On the one hand, facilitating innovation appears in literature and in our empirical work as a value proposition of risk management. On the other hand, it is only one of many value propositions risk management may focus on, and therefore it is not by default the top priority of risk management. The purpose of risk management according to (Bernstein, 1996) is to put the future at the service of the present. Risk management can enable us to understand our risk appetite and perception of uncertainties, and enable us to make sound decisions about the future by supporting decision making and stable project execution (Oehmen et al., 2014). Development of new products is high-risk and the ability to manage risk is crucial for managing innovation (Mu et al., 2009).

The paper is based on insights with industry focus groups interactions (described in Section 2), as well as literature (see Sections 4 and 6). It makes two significant contributions to the discussion of design risk management in the context of innovation. The first contribution, described in Section 3, is to clearly frame innovation as one possible value proposition that is supported by risk management, but which is competing with other, possibly conflicting, value propositions (e.g. project-level cost and schedule minimization). Section 4 presents the literature on possible conflicts between risk management and innovation management. The second major contribution is made by Section 5. It presents our empirical findings on examples of how these conflicts were resolved, with corresponding literature discussion, mainly through re-conceptualizing risk management as a learning strategy and critically discusses these suggestions in light of the literature. Our paper concludes with a summary and outlook in Section 6.

\section{Research method}

To explore the value propositions of RM we conducted 2 focus groups (Blessing and Chakrabarti, 2009) with participants from multiple engineering companies. More than $30 \mathrm{semi}$ structured interviews (Blessing and Chakrabarti, 2009) at different levels in the companies including project management, portfolio management, PMO, risk management, product development, strategy and partnership management. In one of the companies we supported the prototyping of a RM stage gate tool for concept evaluation through iterations using past project knowledge according to methods for the prescriptive phase of the DRM (Blessing and Chakrabarti, 2009). One case study (Yin, 1994) was conducted at a large company studying innovation process and documentation as well as past projects and future pipeline, two case studies in large consumer electronics company at the project $\&$ governance level (one 
currently still running) and one illustrative case study in a small engineering consultancy at the project level interacting with project engineers and a manager. Due to the need for strict confidentiality, the cases and interviewees will not be described in detail. We used grounded theory approach to analyses the data. The data was analysed using affinity diagrams to identify key constructs, in an iterative process.

Table 1. Overview of empirical data collection

\begin{tabular}{|c|c|c|c|}
\hline $\begin{array}{l}\text { Type of } \\
\text { interaction/name }\end{array}$ & Data collection & Company & Focus of interaction \\
\hline Case study A & $\begin{array}{l}\text { Interviews, innovation process } \\
\text { documentation analysis, past projects, } \\
\text { stage gate model prototyping }\end{array}$ & Large engineering & $\begin{array}{l}\text { Value propositions, Section } \\
3 \text {, Section } 4 \text { practice } 1 \text {, } \\
\text { practice } 3\end{array}$ \\
\hline Case study B & $\begin{array}{l}\text { Innovation documentation analysis, } \\
\text { interviews }\end{array}$ & $\begin{array}{l}\text { Large consumer } \\
\text { electronics }\end{array}$ & $\begin{array}{l}\text { Practice 2, Section } 3 \text {, Value } \\
\text { propositions }\end{array}$ \\
\hline Case study C & $\begin{array}{l}\text { Innovation process documentation } \\
\text { analysis }\end{array}$ & $\begin{array}{l}\text { Large consumer } \\
\text { electronics }\end{array}$ & Practice 2, Practice 4 \\
\hline $\begin{array}{l}\text { Case study D } \\
\text { (Illustrative) }\end{array}$ & $\begin{array}{l}\text { Interviews, innovation \& project } \\
\text { documentation }\end{array}$ & $\begin{array}{l}\text { Small engineering } \\
\text { consultancy }\end{array}$ & $\begin{array}{l}\text { Value propositions, Section } \\
3 \text {, Section } 4 \text {, practice } 3\end{array}$ \\
\hline Focus group 1 & & 10 Large + SME's & Value propositions, Section 3 \\
\hline Focus group 2 & & 31 Large + SME's & Value propositions, Section 3 \\
\hline Additional & Interviews & $\begin{array}{l}4 \text { Engineering } \\
\text { companies }\end{array}$ & Section 4 \\
\hline
\end{tabular}

\section{Empirical study of multiple value propositions of design risk management in the context of innovation}

When studying the value of risk management, we found that it has significantly different value propositions for different stakeholder groups, such as "keep project on quality target", "support decision making", "assist the prioritization of efforts", "help to avoid deaths", or "assist exploration of the solution space". We found that these different perceptions lead to conflicts about what value risk management is supposed to provide. We explored the value perceptions of stakeholders in regard to outcomes on the project and strategic level "what to deliver", as well as value perceptions of the RM process itself, "how to deliver" (discussed in more detail in the following sub-sections). For example, stakeholders with finance responsibility focussed on risks to cash flow, while R\&D stakeholders focused on technical risks. These different views affect how a potential innovation is viewed and for instance, what performance parameters are in focus.

\subsection{Empirical findings regarding the outcome related value propositions of risk management}

\subsubsection{Project level impact}

We found that the value of risk management is related to what objectives it may serve to protect. 'Keeping project on target' is a central value proposition of risk management. One stakeholder may focus on a particular impact dimension in relation to project success, such as keeping the project on cost target and another on keeping the project on schedule and this affects what value they see in risk management and how it is performed. The different value propositions can create clashes between stakeholders that show up in the risk management. In one case the engineers focused on technical feasibility risk and the portfolio manager on cost, creating a tension. The categories of impact we identified was: Time, cost, quality, scope, health \& safety, environment and customer satisfaction. Risk management provides value by helping the project manager to prioritize tasks in terms of risks to the target. What target was in focus differed according to project and project context.

\subsubsection{Project context level / strategic impact}

At the project context level the 'value of risk management' was observed to relate to impact dimensions such as determining what innovations are a good fit with the company strategy, but also it was stated that project managers do not prioritize 'higher level' objectives in their projects, potentially creating a 
problematic environment for innovation. The value of risk management was found to differ across company functions. Finance typically focusing on "Keeping the project on cost" while R\&D employees at the project level were more focused on "Exploring the technically feasible solution space" and management on "Being on schedule". At the strategic level in the companies, risk management assisted the prioritization of strategy and the go / no-go decisions about concepts (innovations) and projects at the stage gates. A value of risk management was also to evaluate the risk profile according to 'degree of innovation'. Beyond these we found that aspects of the process quality of RM affect innovation.

At the project context level we identified the following value that RM helps to protect: Growth, market share, profitability, cashflow, innovation, reputation, profitability, culture and compliance.

\subsection{Empirical findings regarding the process quality related value propositions of risk management}

We identified several value propositions of the risk management (RM) that addressed the quality of design process execution. They have a direct impact on how innovation management is executed.

\subsubsection{Assisting the exploration of the (feasible) solution space}

A solution might seem enticing at first, but the stakeholders will need to figure out if it is part of the feasible solution space. Interviewees identified RM to play a central role in this. RM can assist the exploration of the solution space as it can determine if a concept is too risky in relation to a type of potential impact on the project. This could be in terms of 'innovation degree' or potential cost or other. A development team and portfolio manager described RM as a way to understand if a solution would be feasible by understanding how it would affect stakeholders, such as customers and existing production, ultimately placing RM as central to feasibility. In case D, a mechatronic device was developed without any systematic risk management until late in the project. When the risk management was performed in relation to project objectives beyond cost and schedule, the concept was scrapped due to safety regulations and the development efforts set back. A key point that emerged is that it is important to look "beyond cost and schedule". If we focus only on cost and schedule we could reject innovative ideas because the schedule is unknown and the cost is usually "high risk for high long term gain", and may create a conflict between value propositions.

\subsubsection{Risk management supports decision making: The go/no-go decisions}

Risk management was identified to create value by providing information to decision makers. One concrete example brought up by multiple interviewees and cases is the stage gate. Risk management provides value by supporting decision making about to pursue, or not to pursue an idea or project. A value of RM identified in the empirical work is to support decision making. The value of risk management in decision making is linked to evaluating concepts at stage gates, figuring out which risk to address, and inform the strategic level. It can be related to innovation, but doesn't have to be.

\subsubsection{Create transparency regarding risk exposure}

RM helps prioritize task in the "day to day" work of a project manager. When a project manager identifies an important risk, for instance because it is likely to impact soon, or is very high impact, he may choose to perform an action in relation to this risk. The empirical data showed that risk management provides value for many stakeholders in relation to how they prioritize.

\subsubsection{Facilitate high quality requirements}

Better understanding of requirements is a key need for stakeholders in design projects. In the empirical work, we found risk management to be intimately tied to requirements. Examples include a project manager and leadership who used the RM to have conversations about requirement quality. They used the RM artefacts to facilitate an improved understanding of the uncertainty in the requirements captured.

\subsubsection{Enable engineers or project managers to speak up}

The RM was used in a way for engineers or project managers to reach out to the leadership with serious risks, the need for resources or risks going beyond the scope of the project. Risk management 
is of value to the project in relation to risks that cannot be handled by the project, to identify risk that fall 'between two chairs' (i.e. areas of expertise), and to the company as a communication channel.

\subsection{Discussion: Managing the risk to innovation in context of other risk management value propositions}

There may be conflicts between risk management supporting different value proposition. For instance between 'keeping the project on cost, schedule or quality target', and the value proposition of 'exploring the solution space' and supporting innovation and decision making about innovation. Conflicting interests between stakeholders in design projects are the norm, not the exception, and they are reflected in RM. This is seen in the relation between schedule and cost minimization vs. innovation and risk taking on the strategic level as well as in how the process is performed. One of the value propositions identified for risk management is to support innovation. The challenge is that risk management is concerned with a multitude of value propositions, and supporting innovation is one of many. If emphasis is placed on cost, time or reputation by a stakeholder, there may be a trade-off with risk to innovation.

\section{Identification and discussion of failure modes of risk management in innovation}

\subsection{Failure modes of risk management in innovation identified through empirical work}

During empirical work with focus groups and cases, we identified two failure modes of risk management in the context of innovation:

- Failure mode 1: Risk management is perceived to cancel promising concepts too early in the development process before they were explored thoroughly. We have observed in two of the case studies (A, B), that a low risk appetite showed up in the management of risk, particularly at the stage gates, and caused them to kill innovative ideas, that now potentially could disrupt them. Multiple instances of missed opportunities were identified in the cases.

- Failure mode 2: A lack of risk management in the early phases leads to cancellation of projects after long development time due to unresolved and often undiscovered critical risks. The general sentiment was that an earlier involvement of risk management could have either identified and resolved the risk earlier, or the risk could have been identified as critical and notresolvable earlier in order to allow for an earlier cancellation of the project. In case D, concepts were scrapped at the late stages due to lack of work safety and feasibility risk. In case study A, a lack of front loading of risks was described to lead to late cancellations.

It is not without irony that risk management either fails by cancelling possibly feasible ideas too early, or by letting unfeasible ideas progress too far in design. During the empirical work we observed a fundamental struggle in assessing the "risk of innovating" (e.g. spending too much or taking too long on highly innovative projects) compared to the "risk of not innovating" (i.e. saving money by pursuing a more conservative development project pipeline): The observed organizations struggled to clearly articulate the relative risk of these two options. The general focus was on "taking the innovation risk and making it work". However, in cases where innovation ideas were deemed "too risky" or simply "not feasible", there was not structured assessment of the risk of "giving up on innovation". These three observations will be discussed in light of the literature in the following sections:

\subsection{Literature discussion of failure mode 1: Cancelling innovation ideas "too early"}

Even though the management of risk is inherent in innovation management, risk management with a focus on cost, quality and schedule may be unfit and unable to address the uncertainties associated with innovation. It questions the approaches of 'triple constraints', phase gate models' and 'project risk management' (Loch et al., 2006; Dodgson, 2013) and thus there is a paradox between the need for managing risk in innovation projects, and risk management. Many companies rely on milestone structures and stage gates for handling innovation but these tend to stifle innovation because of the risk adverse attitudes often inherent in them. The go/no-go decision gates often employed creates challenges for 'high innovation' strategies (Sharma, 1999). The paradox is that middle managers tend to be responsible for resource allocation for innovation projects but these middle level managers are 
risk averse (Bower, 2014). It is challenging to understand the risk profile of radical and disruptive innovation concepts, and they tend to face a 'standard' risk management review at some stage in the process of product development and design, (ISO, 2009). This can be both good (we save lives) and bad (we kill important projects) but according to (Sharma, 1999; Loch et al., 2006) the review and risk management processes are not adequate for handling innovation. In such situations, "decision makers all too often become risk averse and reliant on known metrics..." (Guenther et al., 2017). It is important to understand that the problem is not RM, but its application conditioned by the understanding (wrong) that RM is about risk-avoidance. To address this (Vasconcellos et al., 2011) recommends tailoring the risk management process to the product innovation degree, product design maturity and the project team, to enable risk management to better support innovation.

\subsection{Literature discussion of failure mode 2: Cancelling unfeasible projects too late $-\mathbf{a}$ lack of risk management in the early stages}

According to (Bowers and Khorakian, 2014), there is very little discussion about explicitly combining risk management and innovation management theories and specific risk management approaches are rarely integrated in the front end development process (Neumann, 2016). Risk management is not a very well acknowledged part of innovation management, and most risk management initiatives are linked to the later stages of innovation (Chapman and Ward, 1996; Goffin and Mitchell, 2005; Ilevbare et al., 2014). A common approach to reduce risk and uncertainties in innovation projects is to not address all the issues of risk and uncertainties concurrently. Another way is to identify which are the most 'important' uncertainties to address first, a typical choice being 'desirability', which as pointed out by multiple authors (Ries, 2011; den Ouden, 2012) is a crucial risk if not addressed properly. Risk management is frequently not present in the early stages because there is a concern that excessive risk management in the early stages could stifle the creativity that is critical for innovation. (Sharma, 1999; Bowers and Khorakian, 2014) The paradox is that innovation management recommends that risk management should not be present in the early phases (Sharma, 1999; Dodgson et al., 2008; Petetin et al., 2010; Dodgson, 2013) although we do implicit risk management when innovating (Bernstein, 1996). When a concept faces a RM review late in the development, important risks could have been frontloaded and addressed earlier (Haughey, 2017). Part of the reason why RM is not integrated at the front-end, may be due to how innovation management perceives risk management. According to Loch et al. (2006) risk management is applicable to highly routine and predictable projects and encourage 'getting back to the plan' rather than learning new things and changing direction. RM is unable to cope with novel or innovative projects because they face major risks that are unknown and cannot be foreseen (Loch et al., 2006). This is a narrow understanding of risk as well as risk management, because risk management is much more (Oehmen et al., 2006, 2014; ISO, 2009; Olechowski et al., 2012). A key aspect of innovation management in design is reducing uncertainty and risk by learning through experimentation strategies (Dodgson, 2013; Tidd and Bessant, 2013) such as 'fail early, fail often, fail cheap' (Ries, 2011). Another experimentation strategy is prototyping to reducing uncertainty on desirability, technical feasibility and economic viability (den Ouden, 2012). These can be seen as risk reduction strategies of making sure that 'right' objectives are pursued (den Ouden, 2012; Raynor, 2016).

\subsection{Literature discussion of the risk of innovating vs. the risk of not innovating}

By selecting to work a long time on the 'wrong' concept without knowing it, companies run the risk of innovating and by deselecting important innovations, companies run the risk of not innovating. Highly-innovative ideas are often referred to as radical or disruptive. The terms radical and disruptive are often used interchangeably to describe innovations that are significantly different from existing alternatives in the market but disruptive innovation represent particularly important risks to companies. Radical and disruptive innovations include certain characteristics, such as the company strategy in addressing a value network and risk of misinterpreting performance parameters (Christensen and Raynor, 2003; Lucas and Goh, 2009; Dodgson, 2013). When dealing with disruptive innovations it is important to understand the risk profile of these innovations. On the one hand, there is risk in pursuing potentially disruptive innovations as they may turn out in an unexpected, unfruitful way. On the other hand, not pursuing potentially disruptive innovations may represent a risk if a 
competitor launches it successfully. The dilemma is weighing "The risk of innovating vs. the risk of not innovating", and the failure mode is getting either wrong. Part of the challenge is how to apply the 'right' risk management and the risk of missing valuable innovation opportunities is very often overlooked in practice. (Ilevbare et al., 2014). The innovation process is often assumed to be well defined, such 'a stage gate'. This may be appropriate for incremental innovation projects but not for radical and disruptive innovations. For high degrees of innovation it is important to consider among other elements, what stakeholders value and how the risk management is carried out (Petetin et al., 2011), i.e. the process quality aspects. Studying cases of introducing a potentially disruptive technology to the market, we find that companies tend to underestimate the risk of not investing in their own innovative inventions. Established companies end up being disrupted by other companies, that perceived the risks differently (Christensen and Raynor, 2003; Lucas and Goh, 2009; Raynor, 2016). Cases of previous disruptions describe how established companies missed the opportunity of a disruptive innovation because they misinterpreted the potential of the innovation and its potential risk to the company. This is e.g. the case for Kodak, who actually invented the digital camera in the 80'es (Lucas and Goh, 2009). There are multiple challenges involved in managing risks in an innovation process - and this is in particular true when dealing with disruptive innovation. Deciding to pursue or not to pursue a highly innovative idea is correlated with degree of uncertainty, interpretation of the risk, risk appetite and the RM. Established companies tend to deal with this kind of uncertainty by making market predictions in order to determine the potential of innovations and reduce risk. According to disruption theory, market predictions are often fruitful in assessing sustaining innovation, however highly imprecise when dealing with disruptive innovations (Christensen, 1997; Christensen and Raynor, 2003). Whereas companies are highly aware of the risk of innovation, the risk of not innovating tends to be overlooked, pointing to a need for improved risk management in innovation. The tendency to stick with what works may be a typical trait of well-established companies. According to (Christensen, 1997), one of the root causes of disruption is actually good management practice.

\subsection{Reflections on the failure modes and value propositions of risk management}

Risk management deals with classic management value propositions as well as innovation, which can conflict. This may be one of the root causes behind the failures of risk management and innovation management to integrate well. Knowledge about the multiple value propositions of risk management and their contradictions, such as between cost minimization on the project level and innovation height at the strategic level, may serve to inform the integration of innovation and risk management to avoid missing valuable opportunities as well as losing resources on redundant projects. A core part of innovation management is about managing uncertainty by reducing the cost of learning, and this can be seen as a risk reduction strategy. Risk management has many value propositions for different stakeholders and is traditionally not perceived as value-adding in the early stages, but is inherent in innovation management. Conceptualised as a learning strategy, risk management can benefit the early stage of the innovation process. The challenge is that there are many value propositions for doing risk management, potentially conflicting about what are the important objectives, process quality and risk appetite and innovation is just one of them. We propose to reconcile innovation management and risk management related to the outcomes and objectives (what to deliver) and the process (how to deliver).

\section{Reframing of risk management in high degree of innovation projects as a learning strategy: Identification of practices from empirical findings}

Section 3 presented our findings that innovation is only one of several value propositions for risk management, and Section 4 presented our empirical and literature findings on failure modes of innovation and risk management integration. This section presents practices observed in focus group interactions and case studies, where organizations reconciled risk management with highly innovative projects. We summarize these practices under the question of: How can we reframe risk management to massively reduce the cost of learning? From this central question, we construct a series of subquestions for the reconceptualization of RM in the following: 


\subsection{Practice 1: Tailoring the risk management to type of innovation}

\subsubsection{Empirical observations}

In the empirical studies, we found that risk management needs tailoring to support radical and disruptive innovation. We observed that applying a stage gate process fits incremental development well, but is not conducive to radical and disruptive innovation. Companies judging their risk management to be supportive of radical innovation realized this and acted on the need for tailoring: They did not apply the same risk management, i.e. rigorous feasibility criteria in early project phases, to radical innovation projects. Instead, risk management knowledge and practices was used to co-create the product, and shape the development process (see the following sections). There is an opportunity and challenge to change the role that the risk management and stage gates plays in the process. In both case studies and in the focus groups there were multiple examples of cancellation of projects at the very late stages due to risk evaluations that were perceived to have added significant value in earlier stages (but now shut down the project). There were cases of missing important disruptive innovation opportunities due to early cancellations. In the case studies it led to the realization by the companies that the risk management process needs to be tailored to support innovation and that the innovation process could benefit from a risk management process that adds value in line with the needs of the innovation process.

\subsubsection{Literature discussion}

The empirical findings are supported by literature which state that risk management needs tailoring for high risk-high return in contrast to low risk / low return projects (Vasconcellos et al., 2011; Škec et al., 2014) and even high risk high return projects are very different from each other. There is no one size fits all (Škec et al., 2014) but the questions that risk management can help address as identified through empirical and literature studies is to articulate clearly risk to what, and benefits in terms of what performance parameters (Willumsen et al., 2017). A value conversation or dialogue approach is needed for these types of risks (Kaplan and Mikes, 2012), about what the focus or key impact category tradeoffs should be considered, and what should be the focus on in high risk/high return as different to low risk/low return. (Vasconcellos et al., 2011) identified the need for tailoring risk management to the degree of innovation, and Christensen (1997) identified the need for a new approach of identifying the 'right' performance parameters and the 'risk' of pursuing the wrong ones. (Petetin et al., 2010) argue taking into account strategic and technical risk aligned with stakeholders and that multiple stakeholders and associated views, technical and strategic risks are not taken into account with classical management tools. The guiding questions we propose to tailor risk management are: How can we differentiate between risk management for high risk/high return and low risk/low return projects?

How can we create a risk management that is able to differentiate between the different value propositions (or impact categories and benefits that stakeholders value) of risk management?

\subsection{Practice 2: Experimental/ discovery-driven approach to risk management in the early stages of innovation}

\subsubsection{Empirical observations}

In the focus groups and interviews we observed that risk management has an important role as gatekeeper in the late stages but needs to become a co-creator of innovation in the early stages.

In one of the cases studies we observed a practice of risk management encouraging experimental exploration projects to understand new fields of knowledge outside the core competences of the company. This served a dual purpose: Discover "unknown unknowns", i.e. new risks that the company was not yet aware of; and provide a first-pass feasibility or risk-assessment of "known unknowns" (i.e. plausible, but unquantified risks). Experimental early feasibility studies were conducted before incorporating the subject of these studies into the actual projects. By learning through exploration, the company reduce risk of incorporating these areas of knowledge or ideas into their projects.

These explorations were described as a 'cheap' way to learn about new ideas and technologies at the preconcept stage and can be seen as an example of how risk management can encourage exploration and support innovation. In another case study, tools such as model based systems engineering where used to 
virtually prototype and explore the conceptualization stage. This enabled the early creation, exploration and testing of a high number of solution concepts instead of a few, thus reducing the risk of proceeding with a suboptimal solution, while increasing the company's absorptive (learning) capacity.

\subsubsection{Literature discussion}

During exploration, feasibility studies can reduce uncertainty and risk of utilizing new knowledge (den Ouden, 2012). Further more they can increase the absorptive capacity of the company potentially reducing risk on the strategy level and improving the ability to evaluate ideas (Cohen and Levinthal, 1990; Dodgson et al., 2008; Parrilli and Alcalde Heras, 2016; Raynor, 2016). A role of risk management can be to encourage active experimentation and explore the solution space by opening it up, rather than close it down. In a context where learning has become cheap - such as through the use of virtual prototypes RM can encourage learning where it is 'cheap' and risk reducing. We propose the following guiding question to establish risk management as a cocreator that argues for a cheap and fast exploration of the solution space and testing: How can we re-conceptualize risk management to being a co-creator in the early stages, in addition to being a gatekeeper in the late stages?

\subsection{Practice 3: Uncertainty identification and prioritization to set learning focus}

\subsubsection{Empirical observations}

The case studies A and D reported that RM can assist innovation in articulating risk to the relevant performance attributes and relevant type of return is important to focus on. One of the case studies identified the apparent need for RM in the early stages, to help them focus their "de-risking", i.e. development and learning activities. This was often overlooked in the cases where risk management was described to "kill innovation" in late project phases. In the course of one case study, we were able to suggest changes to a stage gate portfolio manager to front-load risk management activities and use them to prioritize development activities. The company implemented those changes and subsequently reported a perceived improvement in the quality of concepts in the subsequent phases. This strongly suggests that identifying and prioritizing key risks in early design project phases, and subsequently focussing on reducing their associated uncertainty, is a key value proposition of risk management.

\subsubsection{Literature discussion}

Aligned with our findings, the innovation literature also suggests that prioritizing risks and uncertainties is a key success factor (Ries, 2011; den Ouden, 2012; Dodgson, 2013). This prioritization lies at the heart at making the right or wrong decisions in regard to stopping innovation concepts too late or too early. We argue that it highlights the need for learning and the challenges of reconciling how RM can best provide value for innovation management. What we are generally trying to do in innovation projects is reduce the cost of learning (Ries, 2011; den Ouden, 2012), by identified key uncertainty areas to address.

RM can help articulate the fail early, fail cheap strategy by identifying the prototyping needs (prototyping as a risk/uncertainty/risk search strategy - what is it that I need to prototype for?) (den Ouden, 2012; Dodgson, 2013). Risk management can contribute to innovation management by assisting in identifications of the critical sources of uncertainties or key risks, such as requirements, execution and technical feasibility (Ilevbare et al., 2014). We suggest the following guiding questions to strengthen the "learning support focus" of risk management in innovation: How can risk management contribute to the learning strategy with its ability to identify and prioritize risks and key areas of uncertainties? How can we create a risk management that is able to differentiate between the different value categories (impact categories) and identify the most important to address and prioritize?

\subsection{Practice 4: Tracking the development of uncertainties/support exploration of the solution space}

\subsubsection{Empirical observations}

One of the case study companies replaced a large number of key performance indicators used in the design and development process with a risk burndown chart. They argued that their key progress 
measurement is to track uncertainty reduction along critical performance parameters. These burndown charts also incorporated the separate identification and tracking of critical risks, in order to ensure that (the few) critical risks are also addressed, and not just (the many) lower-impact risks reduced. These charts provided input for the innovation process by supporting the exploration of the solution space through identifying key areas of uncertainty. They also helped shape productive conversations across the stakeholder landscape in the innovation project. Instead of exploring the solution space from a purely technical point of view, focusing the search on those solutions that fit the primary requirement of risk reduction, provides focus and was reported to speed up the innovation process.

\subsubsection{Literature discussion}

(Rossberg, 2016) provides a set of agile metrics for project management and software engineering processes which can be applied as burndown charts of uncertainty and risk tracking and reduction in innovation projects. According to (Cooper and Sommer, 2016) there are important new research opportunities and potential in applying principles such as burndown charts as well as other agile risk and uncertainty methods (Moran, 2014) in project and design contexts beyond the software industry. Key question that emerged: How can we best track the development of key uncertainties and the residual uncertainty of the solution space?

\subsection{Discussion of identified risk management practices}

We have observed multiple ways of operationalizing a learning strategy for instance through combining physical prototyping with agile approaches in one case study, directed prototyping, as well as burndown charts and exploratory pre-concept projects. How to best operationalize RM as a learning strategy must be answered by tailoring the RM approach to the project, the strategic objectives as well as the process quality, for example using the questions proposed. Risk management in the early stages may represent a great underexplored leverage point for increasing learning viewed through the learning organisation lens such as (Senge, 1990) and promote interconnected thinking. Risk management and innovation management is a subset of the learning organisation and their integration could massively reduce the cost of learning and reduce the potential paradoxes in the companies. (Kaplan and Mikes, 2012) argue for key risk score cards and a dialogue approach to address ambiguity in uncertainty and resource allocation directed at critical risks. Such resources could be in the form of directing prototyping towards the uncertainty dimension needed (den Ouden, 2012). Christensen argues, that it is impossible for companies to evaluate the potential of a disruptive innovation through the old standard paradigms. (Christensen, 1997; Christensen and Raynor, 2003; Raynor, 2016) Both in the case studies and in the focus group we found cases of concepts they had turned down, later became a threat to them, when a competitor launched it. By applying a lens of disruption to risk management a discovery-driven approach to risk management could be conceptualized. In two of the case studies, the companies may have decided differently, if they had tested, rather than predicted, the market potential of the innovation. (Bowers and Khorakian, 2014) identifies a gap in combining innovation management theories and risk management theories, which maybe a way to address important challenges related to volatile types of innovation, disruptive and radical. One example is a stage gate process used for incremental development, is perhaps not the way it should be used it for radical or disruptive innovation projects, and this may apply to multiple explicit or implicit RM practices. Our argument is that there is a potential to reshape the role of risk management away from being an idea killer, by solving the needs of innovation management. What innovation needs is massively reduce the cost of learning through exploiting the potential of risk management. Even though we have identified some potential ways of RM as a learning strategy, such efforts would face multiple possibly conflicting value propositions, standardized incompatible RM systems, biased risk appetite, process integration challenges as well as going upstream with regard to the mental models in the field. If, however it is accomplished, the competitive advantage could be substantial.

\section{Summary and conclusion}

In this paper, we presented a literature review on some of the central dilemmas in design risk management and innovation management. Our empirical studies revealed that risk management has multiple value propositions that may conflict and that a value proposition of risk management is to 
support innovation. Our case studies and focus groups showcased several principle ideas for reconceptualizing risk management as a learning strategy guided by key questions. The managerial and practical implications of the research is to address the gap and potential of risk management to bring value to the innovation process by assisting in asking the right questions and drawing attention to the challenges of strategic implementation of risk management and innovation. There is a risk of innovating and there is a risk of not innovating and if the risk management is setup to provide value for the innovation process, there is a greater chance to reduce both. We presented a conceptual idea with 4 principles on how to reconceptualise risk management as a discovery driven learning strategy, while retaining the current value of risk management as a gatekeeper of critical risks they are: 1 . Tailor the risk management to type of innovation, 2. Experimental/discovery-driven approach to risk management in the early stages of innovation, 3. Uncertainty identification and prioritization to set learning focus, 4. Tracking the development of uncertainties/support exploration of the solution space. Through an ongoing case study, the research will continue and prototype new ways of reconceptualising risk management as a learning strategy for highly innovative projects.

\section{Acknowledgments}

The authors gratefully acknowledge the funding support provided by the Brightline Initiative.

\section{References}

Bernstein, P. (1996), Against the gods: the remarkable story of risk, Wiley, New York.

Blessing, L.T.M. and Chakrabarti, A. (2009), DRM, a Design Research Methodology, Focus. https://doi.org/10.1007/978-1-84882-587-1

Boothe, K.O. (2014), "Identifying the Need for Innovation Risk Management", Global Conference on Engineering and Technology Management (GCETM 2014).

Bowers, J. and Khorakian, A. (2014), "Integrating risk management in the innovation project", European Journal of Innovation Management, Vol. 17 No. 1, pp. 25-40. https://doi.org/10.1108/EJIM-01-2013-0010.

Chapman, C. and Ward, S. (1996), "Project risk management: processes, techniques and insights", OCLC Systems Services, Vol. 22 No. 4, pp. 256-262. Available at: http://eprints.soton.ac.uk/35673/

Christensen, C.M. (1997), The Innovator's Dilemma: When New Technologies Cause Great Firms to Fail, Harvard Business School Press, Boston, MA.

Christensen, C.M. and Raynor, M.E. (2003), The Innovator's Solution: Creating and Sustaining Successful Growth, Harvard Business School Press, Boston.

Cohen, W.M. and Levinthal, D.A. (1990), "Absorptive Capacity: A New Perspective on Learning and Innovation”, Administrative Science Quarterly, Vol. 35 No. 1, p. 128. https://doi.org/10.2307/2393553

Cooper, R.G. and Sommer, A.F. (2016), "The Agile-Stage-Gate Hybrid Model: A Promising New Approach and a New Research Opportunity", Journal of Product Innovation Management, Vol. 33 No. 5, pp. 513-526. https://doi.org/10.1111/jpim.12314

den Ouden, E. (2012), Innovation Design: Creating value for People, Organizations and Society, Springer. https://doi.org/10.1007/978-1-4471-2268-5

Dodgson, M. (2013), The Oxford Handbook of Innovation Management.

Dodgson, M., Gann, D. and Salter, A. (2008), The Management of Technological Innovation: Strategy and Practice, Oxford University Press, Oxford, United Kingdom, p. 373.

Ettlie, J.E., Bridges, W.P. and O'Keefe, R.D. (1984), “Organization Strategy and Structural Differences for Radical Versus Incremental Innovation", Management Science, Vol. 30 No. 6, pp. 682-695. https://doi.org/10.1287/mnsc.30.6.682

Goffin, K. and Mitchell, R. (2005), Innovation Management: Strategy and Implementation Using the Pentathlon Framework, Palgrave Macmillan, New York.

Guenther, A., Eisenbart, B. and Dong, A. (2017), "Creativity As a Way To Innovate Successfully”, Proceedings of the 21st International Conference on Engineering Design (ICED 17), August 21-25, 2017, Vol. 8, pp. 389-398.

Haughey, B. (2017), "Linking design reviews with FMEA to quickly mitigate the risk of change...design review based on failure modes", Proceedings - Annual Reliability and Maintainability Symposium. https://doi.org/10.1109/RAM.2017.7889706

Ilevbare, I.M., Probert, D. and Phaal, R. (2014), "Towards risk-aware roadmapping: Influencing factors and practical measures", Technovation, Vol. 34 No. 8, pp. 399-409. https://doi.org/10.1016/j.technovation.2014.05.006

ISO (2009), ISO 31000:2009 Risk management - Principles and guidelines, ISO, Geneva, Switzerland.

Kaplan, R.S. and Mikes, A. (2012), Managing risks: A new framework. [online] Harvard Business Review. 
Available at: https://hbr.org/2012/06/managing-risks-a-new-framework

Loch, C.H., De Meyer, A. and Pich, M.T. (2006), Managing the Unknown, Managing the Unknown: a New Approach To Managing High Uncertainty and Risk in Projects, John Wiley \& Sons, Inc. Hoboken, NJ, USA.

Lucas, H.C. and Goh, J.M. (2009), "Disruptive technology: How Kodak missed the digital photography revolution", Journal of Strategic Information Systems, Vol. 18 No. 1, pp. 46-55. https://doi.org/10.1016/j.jsis.2009.01.002

Moran, A. (2014), Agile risk management, Springer International Publishing.

Neumann, M. (2016), "Risk-oriented development of innovative products: a model-based approach", Norddesign.

Oehmen, J. and Seering, W. (2011), "Risk-Driven Design Processes: Balancing Efficiency with Resilience in Product Design", In: Birkhofer, H. (Ed.), The Future of Design Methodology, Springer, pp. 44-54. https://doi.org/10.1007/978-0-85729-615-3

Oehmen, J., Dick B., Lindemann, U. and Seering, W. (2006), "Risk Management in Product Development Current Methods", Proceedings of the DESIGN 2006 / 9th International Design Conference, Dubrovnik, Croatia, The Design Society, Glasgow, pp. 1551-1558.

Oehmen, J., Olechowski, A., Kenley, C.R. and Ben-Daya, M. (2014), “Analysis of the effect of risk management practices on the performance of new product development programs", Technovation, Vol. 34 No. 8, pp. 441453. https://doi.org/10.1016/j.technovation.2013.12.005

Olechowski, A., Oehmen, J., Seering, W. and Ben-Daya, M. (2012), "Characteristics of successful risk management in product design", Proceedings of the DESIGN 2012 / 12th International Design Conference, Dubrovnik, Croatia, The Design Society, Glasgow, pp. 269-278.

Parrilli, M.D. and Alcalde Heras, H. (2016), "STI and DUI innovation modes: Scientific-technological and context-specific nuances", Research Policy, Vol. 45 No. 4, pp. 747-756. https://doi.org/10.1016/j.respol.2016.01.001

Paté-Cornell, M.E. (1996), "Uncertainties in risk analysis: Six levels of treatment", Reliability Engineering \& System Safety, Vol. 54 No. 2-3, pp. 95-111. https://doi.org/10.1016/S0951-8320(96)00067-1

Petetin, F., Bertoluci, G. and Bocquet, J.C. (2010), "A value approach in innovative product development: Are conventional methods and tools sufficient?", Proceedings of the DESIGN 2010 / 11th International Design Conference, Dubrovnik, Croatia, May 17-20, 2010, The Design Society, Glasgow, pp. 403-412.

Petetin, F., Bertoluci, G. and Bocquet, J.C. (2011), "Decision-Making in Disruptive Innovation Projects: a Value Approach", International Conference On Engineering Design (ICED 11), Technical University Of Denmark, Copenhagen, Denmark, August 15-18, 2011.

PMI (2013), "PMBOK”, PMBOK, 53, pp. 1689-1699.

Raynor, M.E. (2016), "Strategic Risk: The Risks "of” and "to" a Strategy: The Case of Blockbuster and the Need for Strategic Flexibility”, Enterprise Risk Management, pp. 219-230.

Ries, E. (2011), The Lean Startup: How Today's Entrepreneurs Use Continuous Innovation to Create Radically Successful Businesses, Crown Business.

Rossberg, J. (2016), "Metrics in Agile Projects", Agile Project Management using Team Foundation Server 2015, Apress, Berkeley, CA, pp. 131-145. https://doi.org/10.1007/978-1-4842-1870-9_7

Senge, P. (1990), The fifth discipline: The art and practice of learning, Doubleday, NY.

Sharma, A. (1999), "Central dilemmas of managing innovation in large firms", California Management Review, Vol. 41 No. 3.

Škec, S., Štorga, M., Rohde, D. and Marjanović, D. (2014), "Tailoring Risk Management Approach for the Product Development Environment", Proceedings of the DESIGN 2015 / 13th International Design Conference, Dubrovnik, Croatia, The Design Society, Glasgow, pp. 385-396.

Tidd, J. and Bessant, J. (2013), Managing Innovation: Integrating Technological, Market and Organizational Change, 5th ed., Wiley, p. 680.

Vasconcellos, V., Grubisic, F. and Gidel, T. (2011), "Recommendations for Risk Identification Method Selection According To Product Design and Project Management Maturity, Product Innovation Degree and Project”, International Conference On Engineering Design (ICED 11), Technical University Of Denmark, Copenhagen, Denmark, August 15-18, 2011.

Willumsen, P., Oehmen, J., Rossi, M. and Welo, T. (2017), "Applying lean thinking to risk management in product development", Proceedings of the 21st International Conference on Engineering Design (ICED 17), Vancouver, BC, Canada, August 21-25, 2017.

Yin, R.K. (1994), Case Study Research: Design and Methods, 2nd ed., Applied Social Research Methods Series.

Pelle Lundquist Willumsen, PhD student

Technical University of Denmark, Management Engineering

Produktionstorvet 424 room 022, 2800 Lyngby, Denmark

Email: pwil@dtu.dk 